\title{
Nutritional Antioxidants and Lipid Profile in Newly Diagnosed Rheumatoid Arthritis Patients
}

\author{
Manjunatha Goud BK, ${ }^{\text {a }}$ Sarsina Devi O, b Bhavna N, c Devaki RN, ${ }^{d}$ Deepa K, ${ }^{d}$ Niveditha Se \\ aDepartment of Biochemistry, Ras Al Khaimah Medical Health Science University, Ras Al Khaimah, U.A.E \\ ${ }^{b}$ Department of Nursing, Vidya Nursing College, Udupi, Karnataka, India \\ 'Department of Pathology, KMC, Manipal University, Manipal, Karnataka, India \\ ${ }^{d}$ Department of Biochemistry, JSS Medical College, JSS University, Mysore, India. \\ 'Department of Pathology, MMMC, Manipal University, Manipal, Karnataka, India
}

\begin{abstract}
Introduction: Rheumatoid arthritis (RA) is a chronic progressive autoimmune disorder characterized by symmetric erosive synovitis. The pathogenesis of bone erosion and joint deformities are not fully understood. The aim of this study was to find out vitamin $C$ and $E$ levels along with the lipid profile in newly diagnosed cases of RA. Materials and Methods: The patients for the study were selected from individuals attending the routine checkup in an Outpatient Department. Based on the criteria led by the American Rheumatism Association (ARA), the newly diagnosed patients were taken as cases and other normal individuals were taken as control group in the study. A total of 50 subjects were included in the study with the age group of $48 \pm$ six years for both genders. Serum Vitamin-E was determined by the colorimetric method and serum Vitamin- $C$ was estimated by the dinitro phenyl hydrazine method. Serum total cholesterol, HDL-cholesterol, triglycerides, and VLDL levels were estimated by the enzymatic method. LDL- cholesterol was calculated by the Friedewald's formula. Results: The levels of nutritional antioxidants vitamin $\mathrm{E}$ and $\mathrm{C}$ were different significantly in RA patients compared to control group. The lipid profile parameters were also different significantly in RA patients compared to the controls. Conclusion: Patients with RA presented with an imbalance in the oxidant-antioxidant system that markedly increased lipid peroxidation products and significantly decreased lipid soluble antioxidant vitamin E. These changes might play a role in the tissue damage and inflammation process in this disease.
\end{abstract}

KEY WORDS: Nutritional antioxidants, Rheumatoid arthritis, Lipid profile

\section{INTRODUCTION}

Rheumatoid arthritis (RA) is a chronic progressive autoimmune disorder characterized by symmetric erosive synovitis. ${ }^{1}$ Exact reasons behind bone erosion and joint deformities are not fully understood. Formation of reactive oxygen species and lipid peroxides as a result of disease activity may play an important role in RA. The antioxidants which prevent damage by free radicals have been shown to be decreased and one of the reasons for occurrence of RA. $^{2}$

RA is characterized by persistent inflammation in the synovial membranes of joints, associated with migration of activated phagocytes and other leukocytes into synovial and periarticular tissue. ${ }^{3}$

Corresponding author:

Dr. B.K. Manjunatha Goud

Assistant Professor

Department of Biochemistry

Ras Al Khaimah Medical Health Sciences University

Ras Al Khaimah

U.A.E - 11172

Mobile no:+971554195204

Email: drmanjunathag@gmail.com
During phagocytosis, monocytes, neutrophils and macrophages generate superoxide radicals, hydrogen peroxide and the highly reactive hydroxyl radicals. ${ }^{4}$ These cytotoxic reactive oxygen species (ROS) may cause oxidative damage in the cells. ${ }^{5}$ Activated oxygen intermediates together with highly reactive radicals, such as the hydroxyl radicals, are able to destroy membrane lipids, proteins, deoxyribonucleic acid, hyaluronic acid, and cartilages. ${ }^{6}$ Enzymatic mechanisms include superoxide dismutase (SOD), catalase and glutathione peroxidase (GPX). Vitamins A, C, E and glutathione are some of the major non-enzymatic antioxidants in the body. ${ }^{7,8}$ Studies have shown that concentrations of vitaminC, vitaminEandbeta-carotene were found to be decreased in patients with RA..$^{9,10}$

This study was conducted to determine the vitamin $\mathrm{C}$, E levels and the lipid profile in newly diagnosed cases of RA patients.

\section{MATERIALS AND METHODS}

The patients for the study were selected from individuals attending the routine checkup in the Outpatient Department, and the study duration was one year. Diagnosis of RA patients was done based on clinical history such as morning stiffness in and around 
joints, serological investigation like serum rheumatoid factor and radiographic changes such as erosions or unequivocal bony decalcification on hands and wrists. Based on criteria led by American Rheumatism Association (ARA), the newly diagnosed patients were taken as cases in the study and other individuals were taken as controls. After obtaining the institutional ethical committee clearance, with the informed consent for both cases and controls, the fasting blood samples were taken.

A total of 50 subjects were included in the study with the age group of $48 \pm 6$ years for both genders. Exclusion criteria were those having clinical history of the diseases such as diabetes mellitus, cardiovascular diseases, inflammatory diseases, infectious diseases, and already diagnosed cases of RA. Control subjects as well as RA patients were not on vitamin, minerals, any drug or such supplementation, which may alter antioxidant levels.

Blood samples obtained from the subjects were centrifuged at $3000 \mathrm{rpm}$ for 5 minutes and theplasmawas Serum total cholesterol, HDL-cholesterol, triglycerides, and VLDL levels were estimated by the enzymatic method. ${ }^{13}$ LDL-cholesterol was calculated by the Friedewald's formula. ${ }^{14}$

\section{Statistical Analysis}

Statistical analysis was done using students t-test and the values expressed as mean \pm SD. Correlation between the variables was estimated by Pearson's correlation coefficients. SPSS 13.0 version was used for the analysis.

\section{RESULTS}

The results of the study were shown in Table 1 . The levels of nutritional antioxidants were decreased significantly (Vitamin E- $p<0.001$ and Vitamin C$\mathrm{p}<0.05)$ in RA patients when compared to control group. Furthermore, the lipid profile parameters such as the cholesterol and LDL levels were statistically significant $(p<0.001)$ in cases when compared to controls. Total cholesterol, triglycerides, LDL cholesterol and VLDL cholesterol were significantly elevated whereas HDL cholesterol was significantly reduced.

Table 1: Values of nutritional antioxidants and lipid profile in study subjects

\begin{tabular}{|lll|}
\hline Parameters & Controls $\mathrm{n}=\mathbf{2 5}($ Mean $\mathbf{\pm S D})$ & Cases $\mathbf{n}=\mathbf{2 5}$ (Mean \pm SD) \\
\hline & & \\
Age (Years) & $55 \pm 12$ & $65 \pm 10$ \\
Total Cholesterol $(\mathrm{mg} / \mathrm{dl})$ & $178 \pm 44.24$ & $246 \pm 55.63^{* * *}$ \\
Triglycerides $(\mathrm{mg} / \mathrm{dl})$ & $112 \pm 21.78$ & $170.20 \pm 29.10^{*}$ \\
HDL Cholesterol $(\mathrm{mg} / \mathrm{dl})$ & $55 \pm 8.03$ & $35.22 \pm 6.44^{* *}$ \\
LDL Cholesterol $(\mathrm{mg} / \mathrm{dl})$ & $110.65 \pm 11.30$ & $154 \pm 30.55^{* * *}$ \\
VLDL Cholesterol $(\mathrm{mg} / \mathrm{dl})$ & $33.45 \pm 7.98$ & $55.45 \pm 9.7^{* *}$ \\
Vitamin E $(\mathrm{mg} / \mathrm{dl})$ & $1.65 \pm 0.45$ & $0.46 \pm 0.11^{* * *}$ \\
Vitamin C (mg/dl) & $0.85 \pm 0.33$ & $0.61 \pm 0.20^{*}$ \\
& & \\
\hline
\end{tabular}

${ }^{*} \mathrm{P}<0.05,{ }^{* *} \mathrm{P}<0.01,{ }^{* * *} \mathrm{P}<0.001$ when compared to the control group

\section{DISCUSSION}

Should rheumatologists be caring their patient's cardiovascular and lipid status? The answer to this question is 'yes'. Several studies suggested that cardiovascular diseases accounted for about half of all deaths in RA. ${ }^{15,16}$ Cardiovascular deaths are more pronounced in the younger age group ( $<55$ years), and may contribute to the substantial reduction in life expectancy, with estimates of standardized mortality ratios ranging from 1.1 to $3 .{ }^{16}$

This increased cardiovascular risk in RA patients could be from several causes. Firstly, the prevalence of new or established cardiovascular risk factors, such as dyslipidemia, diabetes mellitus, hypertension, higher body mass index (BMI), higher waist to hip-ratio or impaired physical fitness, might be increased. ${ }^{17,18}$ Secondly, under treatment of risk factors may play a role. ${ }^{19}$ Finally, RA itself, particularly its chronic inflammatory component, could be an independent cardiovascular risk factor. ${ }^{20}$.

In our study, we found a deranged lipid profile in RA patients which favours atherogenesis even in the newly diagnosed RA patients.

Previous studies suggested that cardiovascular disease in RA may result from accelerated atherosclerosis caused by clinical or subclinical vasculitis. The main determinants of cardiovascular risk in the general population, however, are the concentrations of serum low-density lipoprotein (LDL) and high-density lipoprotein (HDL) cholesterol. In men who are middle-aged or over, a ratio of total to HDL cholesterol over 5 is associated with increased risk of a first myocardial infarction. ${ }^{5}$ Oxidative modification of LDL may also be important, and it is of interest that 
oxidised LDL has been noted in RA synovial biopsy specimens. These oxidised products have to be neutralized by antioxidants present in the body, which was evident in our study, as vitamin $E$ and $C$ levels were decreased in RA patients. This was in agreement with a study done by Heliovaara et al. ${ }^{21}$ which demonstrated that a low antioxidant level was a risk factor for development of RA disease. It is possible that vitamin $E$ was consumed in the process of counter-balancing the free radicals. A decrease in plasma vitamin $E$ was also observed in juvenile rheumatoid arthritis. ${ }^{9}$

Vitamin C is one of the most efficient water soluble antioxidants. Our findings revealed that the levels of vitamin C in RA patients decreased significantly when compared to controls and was in accordance with Situnayake et al. ${ }^{22}$ who reported a significant decrease in plasma vitamin C levels in RA patients with moderately active inflammatory activity, and 70\% of these patients were seropositive for rheumatoid factor.

The inflammatory environment and disturbed antioxidant mechanisms in RA8 may promote LDL oxidation, thereby facilitating atherogenesis at lower ambient lipid concentrations and placing RA patients at higher cardiovascular risk.

\section{CONCLUSION}

We conclude that patients with RA present with an imbalance in the oxidant-antioxidant system that markedly increased lipid peroxidation products and significantly decreased lipid soluble antioxidant vitamin $\mathrm{E}$. These changes might play a role in the tissue damage and inflammation process in this disease.

\section{REFERENCES}

1. Taysi S, Polat F, Gul M, Sari RA, Bakan E. Lipid peroxidation, some extracellular antioxidants and antioxidant enzymes in serum of patients with rheumatoid arthritis. Rheumatol Int 2002;21:200-4.

2. Sklodowska M, Gromadzińska J,Biernacka $M$,et al. Vitamin E, thiaobarbituric acid reactive substance concentrations and Super oxide Dismutase activity in the blood of children with juvenile rheumatoid arthritis. Clin Exp Rheumatol 1996;14:433-9.

3. Mulherin D, Fitzgerald O, Bresnihan B. Synovial tissue macrophage populations and articular damage in rheumatoid arthritis. Arthritis Rheum 1996;39:115-24.

4. Rowley D, Gutteridge JM, Blake D, Farr M, Halliwell B. Lipid peroxidation in rheumatoid arthritis: thiobarbituric acidreactive material and catalytic iron salts in synovial fluid from rheumatoid patients. Clin Sci 1984;66:691-5.

5. Parke DV, Sapota A. Chemical toxicity and Volume 11 Number 1 June 2012 reactive oxygen species. Int J Occup Med Environ Health 1996;9:331-40.

6. Biemond P, Swaak AJ, Penders JM, Beindorff CM, Koster JF. Superoxide production by polymorphonuclear leucocytes in rheumatoid arthritis and osteoarthritis: in vivo inhibition by the antirheumatic drug piroxicam due to interference with the activation of the NADPH- oxidase. Ann Rheum Dis 986;45:24955.

7. Thabrew MI, Senaratna L,Samarawickrema $\mathrm{N}$, Munasinghe $\mathrm{C}$. Antioxidant potential of two polyherbal preparations used in Ayurveda for the treatment of rheumatoid arthritis. J Ethnopharmacol 2001;76:285-91.

8. Halliwell B. Free radicals antioxidants in human disease curiosity, cause, or consequence. Lancet 1994;344:721-4.

9. Ashour M, Salem $\mathrm{S}$, Hassaneen $\mathrm{H}$, et al. Antioxidant status in children with juvenile rheumatoid arthritis (JRA) living in Cairo, Egypt. Int J Food Sci Nutr 2000;51:85-90.

10. Araujo V, Arnal C, Boronat M, Ruiz E, Domin guez $\mathrm{C}$. Oxidant-antioxidant imbalance in blood of children with juvenile rheumatoid arthritis. Biofactors 1998;8:155-9.

11. Baker and Frank. Determination of serum tocopherol by colorimetric method. In: Varley's practical clinical biochemistry. Heinmann Professional Publishing; $6^{\text {th }}$ Edition 1988: 902.

12. Tietz NW. In: Text book of clinical chemistry. Philadelphia: Saunders, 1986: 900-2.

13. Wybenga DR, Pileggi VJ, Dirstine PH, Di Giorgio J. Direct manual determination of serum total cholesterol with single stable reagent. Clin Chem 1970;16(12):980-4.

14. Friedewald WT, Levy RI, Fredrickson DS. Estimation of the concentration of low density lipoprotein - cholesterol in plasma, without use of the preparative ultracentrifuge. Clin Chem 1972;18:499-502.

15. Reilly PA, Cosh JA, Maddison PJ, Rasker JJ, Silman AJ. Mortality and survival in rheumatoid arthritis: a 25 year prospective study of 100 patients. Ann Rheum Dis 1990;49:363-9.

16. Myllykangas-Luosojarvi RA, Aho K, Isomaki HA. Mortality in rheumatoid arthritis. Semin Arthritis Rheum 1995 Dec;25(3):193-202.

17. Dessein PH, Joffe BI, Veller MG, et al. Traditional and nontraditional cardiovascular risk factors are associated with atherosclerosis in rheumatoid arthritis. $J$ Rheumatol 2005;32(3):435-42.

18. Goodson NJ, Solomon DH. The cardiovascular manifestations of rheumatic diseases. Curr Opin Rheumatol 2006;18: 135-40.

19. Boers M, Dijkmans B, Gabriel S, et al. Making an impact on mortality in rheumatoid arthritis: targeting cardiovascular comorbid ity. Arthritis Rheum 2004;50:1734-9. 
20. Maradit-Kremers H, Nicola PJ, Crowson CS, Ballman KV, Gabriel SE. Cardiovascular death in rheumatoid arthritis: a population-based study. Arthritis Rheum 2005;52:722-32.

21. Heliovaara $M$, Knekt $P$, Aho K, et al. Serum antioxidants and risk of rheumatoid arthritis. Ann Rheum Dis 1994;53:51-3.

22. Situnayake RD, Thurnham DI, Kootathep S, et al. Chain breaking antioxidant status in rheumatoid arthritis: clinical and laboratory correlates. Ann Rheum Dis 1991;50:81-6. 